\title{
Práticas indígenas de cura no Nordeste brasileiro: discutindo políticas públicas e intermedicalidade
}

João T. Andrade e Carlos Kleber Saraiva de Sousa

\section{(2) OpenEdition \\ 1 Journals}

Edição electrónica

URL: http://journals.openedition.org/aa/2581

DOI: 10.4000/aa.2581

ISSN: 2357-738X

Editora

Programa de Pós-Graduação em Antropologia Social (UnB)

\section{Edição impressa}

Data de publição: 1 dezembro 2016

Paginação: 179-204

ISSN: 0102-4302

\section{Refêrencia eletrónica}

João T. Andrade e Carlos Kleber Saraiva de Sousa, «Práticas indígenas de cura no Nordeste brasileiro: discutindo políticas públicas e intermedicalidade», Anuário Antropológico [Online], v.41 n.2 | 2016, posto online no dia 15 junho 2018, consultado o 27 abril 2021. URL: http://journals.openedition.org/aa/2581 ; DOI: https://doi.org/10.4000/aa.2581

\section{(c) (i) $९$}

Anuário Antropológico is licensed under a Creative Commons Atribuição-Uso Não-Comercial-Proibição de realização de Obras Derivadas 4.0 International. 


\section{Práticas indígenas de cura no Nordeste brasileiro: discutindo políticas públicas e intermedicalidade}

João T. Andrade

UECE

Carlos Kleber Saraiva de Sousa

UFC

Nas décadas recentes, a medicina tradicional indígena tem recebido um reconhecimento internacional como parte crescente dos sistemas de cuidados em saúde. Sua importância vem da efetividade de seus métodos, de uma significativa presença cultural e da cooperação com os serviços biomédicos, especialmente na atenção primária em saúde (Bodeker \& Gemma, 2007; Garnelo \& Pontes, 2012; Martin-Hill, 2009). Mais ainda, as práticas indígenas têm tido o apoio de diversas agências de saúde (Brasil, 2007b; WHO, 2002, 2005). Eficácia terapêutica, financiamento, qualificação de terapeutas, políticas públicas e patenteamento de ingredientes vegetais estão no debate sobre a medicina tradicional indígena relativa ao campo da saúde pública, para planejadores em saúde e para os povos indígenas.

Neste contexto, há uma crescente defesa da integração da medicina tradicional ao conjunto de saberes e serviços da medicina alopática. Como esta empresa, proposta por governos e agências de saúde, considera os povos indígenas e seus curadores? Quais são as características, vantagens e limitaçôes desta integração? Como as comunidades indígenas lidam com esta questão na vida diária? Este artigo póe em relevo o papel da medicina tradicional indígena no setor de saúde pública no Brasil, examinando as políticas públicas e as diretrizes de saúde voltadas para os povos indígenas. Esta discussão está baseada em uma análise do pluralismo médico e da intermedicalidade, sublinhando a interface entre cuidados em saúde e saberes ocidentais e indígenas.

O termo "intermedicalidade" origina-se do estudo antropológico de Shane Greene (1998) sobre o xamanismo na América do Sul. O autor emprega a noção de intermedicalidade para examinar as interseçôes entre os sistemas de saúde biomédicos e indígenas e para demonstrar a importância do agenciamento dos curadores Aguarana no Peru. Greene conceitua intermedicalidade como "um espaço contextualizado de medicinas híbridas e agentes sociomedicamente conscientes" (1998: 641) e agrega que os sistemas médicos são inseparáveis dos interesses socioideológicos. A ênfase em "agentes conscientes" sinaliza para 
o importante fato de que as pessoas exercem liberdade para manejar recursos e práticas terapêuticas no enfrentamento das enfermidades. Greene ressalta ainda o reconhecimento do pluralismo médico (a diversidade de cuidados em saúde) e os esforços pela integraçáo entre etnomedicina e biomedicina, orientados por gestores das políticas públicas e pela Organização Mundial da Saúde (OMS). Mas também destaca que a integração significa uma forma de domínio neocolonial sobre a etnomedicina e os saberes indígenas.

Por sua vez, Maj-Lis Follér (2004) denomina intermedicalidade a zona de contato entre a biomedicina e o conhecimento tradicional indígena. O termo "zona de contato", tomado de Mary Louise Pratt, póe em relevo o espaço de encontros coloniais, em que atuam colonizadores e colonizados, em meio a interaçóes e relaçôes de poder. Considerando estudos sobre os povos indígenas da Amazônia, Follér salienta que o espaço da intermedicalidade comporta ambivalências e fusão de conhecimentos, e que os povos indígenas não são sujeitos passivos perante o conhecimento biomédico ocidental. Follér sustenta que o encontro médico entre biomedicina e etnomedicina constrói novas formas de hibridismo, e que as epistemologias subjacentes a estes sistemas médicos têm se misturado em muitos casos. Disto resulta que a medicina híbrida contém características tanto da biomedicina quanto da etnomedicina. Adicionalmente, pesquisas conduzidas no Brasil fazem uso do conceito de intermedicalidade para examinar curas xamânicas (Rose, 2006) e programas de saúde para populações indígenas (Novo, 2011). Estes estudos enfatizam o intercâmbio entre práticas de saúde e sistemas médicos, além dos conflitos que emergem destes contextos sociais.

Para o propósito deste artigo, analisamos o caso do povo Pitaguary no Nordeste brasileiro e seus saberes tradicionais de cura, considerando que os cuidados em saúde se revestem de complexidade e são conduzidos em um cenário intercultural. Sustentamos que a integração de sistemas médicos configura um empreendimento impositivo e limitado, guiado por agências governamentais de saúde no Brasil, mesmo que tal esforço venha em resposta às lutas indígenas por serviços sanitários e por qualidade da saúde. Por outro lado, a intermedicalidade ilumina práticas efetivas e cotidianas em comunidades locais, acontecendo parcialmente independente das políticas públicas de saúde. A intermedicalidade realça várias práticas de saúde com significado étnico para os povos indígenas, e isto ocorre em um contexto de diversidade terapêutica e hibridismo cultural. As práticas indígenas de cura, como assumidas pelos Pitaguary, atuam com outra forma de racionalidade, bem distinta daquela da biomedicina. Tal condição marca uma diferenciação não somente nas condutas diagnóstico-terapêuticas, mas no modo como são consideradas as pessoas, a natureza e a espiritualidade. 
Neste artigo, contextualizamos a medicina tradicional indígena relativa à saúde pública. Analisamos criticamente o discurso oficial das agências sanitárias sobre a integração de sistemas médicos no Brasil. Sustentamos que as ações das políticas públicas voltadas para a saúde indígena promovem um limitado intercâmbio, ao invés de uma integração, como está instituído pela política nacional indígena. Finalmente, pomos em relevo as práticas de cura dos Pitaguary na zona rural cearense a fim de compreender o uso de recursos terapêuticos pela comunidade, que é exemplo de intermedicalidade na vida diária e constitui fenômeno diverso do que sugerem os esforços oficiais pela integração.

Os Pitaguary constituem uma combativa comunidade no Ceará, entre outros grupos nativos, com forte liderança na defesa de seus direitos. Os Pitaguary são um dos 11 povos $^{2}$ indígenas existentes no estado, que totalizam 22.216 pessoas, segundo a Secretaria Especial de Saúde Indígena (Sesai). Eles habitam área de 1.735 hectares nos municípios de Maracanaú e Pacatuba, distantes $20 \mathrm{~km}$ de Fortaleza, capital do Ceará. Os Pitaguary reúnem 3.374 pessoas, distribuídas em 6 comunidades. Parte de suas terras inclui a serra da Aratanha, área de floresta usada para caça, agricultura e rituais religiosos. Os Pitaguary também sobrevivem da pesca e do artesanato, vivendo em zona de sertão, mas bem próximo de uma grande área industrial. A comunidade Monguba, onde conduzimos a pesquisa de campo, situa-se ao longo da linha férrea, local em que habitam cerca de 700 pessoas.

Após 20 anos de luta, os Pitaguary conseguiram parcialmente a demarcação de suas terras, escolas indígenas, serviços de saúde e assistência social. Mas ainda enfrentam problemas com discriminação social e invasões de suas terras. Em 2011, quando da $17^{\text {a }}$ Conferência dos Povos Indígenas no Ceará, os Pitaguary e outras comunidades reivindicaram água potável, obras de saneamento e mais profissionais nas unidades de saúde. Acrescente-se que eles firmaram grande importância à espiritualidade e a seus rituais tradicionais como instrumentos para proteger suas terras e sua cultura.

Esta reflexão tem por base pesquisa realizada entre 2010 e 2012. ${ }^{3}$ O estudo combinou exame de políticas públicas e saúde indígena, com acesso a websites de instituiçóes (Sesai, Funasa, Funai) e de organizaçóes indígenas, além do levantamento bibliográfico da literatura especializada. ${ }^{4} \mathrm{O}$ material empírico resulta de etnografia conduzida com os Pitaguary, que envolveu participação em cerimônias e rituais, entrevistas e grupos focais, com visitas a unidades de saúde da Estratégia Saúde da Família (Esf) e do Distrito Sanitário Especial de Saúde Indígena (Disei). Os curadores Pitaguary (rezadores, curandeiros, parteiras, raizeiros) são reconhecidos por outros grupos indígenas no Ceará. É deles a fonte 
principal das narrativas examinadas neste trabalho. Práticas indígenas de cura é o conceito escolhido neste artigo, contemplando cuidados e ações terapêuticas cotidianas dos povos indígenas (Pappas, Baydala \& Smythe, 2007; Waldran, Herring \& Young, 2006) em sua manifesta pluralidade.

\section{Práticas indígenas de cura: questáo relevante para a saúde pública}

O entendimento da medicina tradicional no mundo moderno, como questáo sociológica, não está restrito ao exame de disputas políticas por opçôes terapêuticas ou à inevitável condiçáo dos pobres para lidar com as doenças e garantir boa saúde e sobrevivência. Mais ainda, este constitui um cenário onde a pluralidade terapêutica — na qual as práticas de saúde têm lugar — traz à luz uma diversidade epistemológica. Neste debate, a biomedicina deve ser entendida no contexto da colonizaçáo e do eurocentrismo. Ao mesmo tempo, a medicina tradicional, em sua diversidade de usos e tecnologias, apresenta-se como conhecimento local e comunitário, marcado pela pluralidade de modos de conhecimento sobre a vida, a morte e a transcendência.

A OMS tem reconhecido a medicina tradicional e a medicina complementar/ alternativa como importantes opçôes terapêuticas para a saúde pública. Ambas têm longas raízes culturais, assentadas em práticas indígenas e/ou em sistemas como o Ayurveda indiano, a medicina clássica chinesa e várias formas de xamanismo. O termo "medicina tradicional" refere-se a "práticas, abordagens, saberes e crenças que, incorporando medicinas com o uso de várias plantas, animais e/ou minerais, terapias espirituais, técnicas e exercícios manuais", utilizados para o diagnóstico e a cura de várias enfermidades (WHO, 2002: 7).

Entretanto, o conceito de medicina tradicional tem sido criticado seja pelo peso colonial que o termo tradicional carrega (Martin-Hill, 2003, 2009), seja por sua desatualização no contexto contemporâneo (Waldram; Herring \& Young, 2006), seja ainda porque a articulação entre "medicina" e "tradicional" é problemática, pois a medicina está vinculada ao paradigma científico, contrastando com as práticas de cura indígenas. Ademais, os saberes indígenas corporificam uma "ciência sustentável” (Broadhead \& Howard, 2011), baseada na visáo de mundo indígena e na maneira como estes povos exploram o mundo natural. Logo, isto significa uma ciência diversa, distinta do paradigma dominante. Ainda que problemático, o termo "tradicional” não pode ser evitado neste debate.

De outra parte, a definição da OMS não inclui substancialmente os aspectos étnicos destes recursos terapêuticos. É importante ter em conta que os saberes 
indígenas existem por transmissão oral, tendo forte caráter empírico e uma abordagem holística na qual intuição e espiritualidade estão implicadas. Em antropologia, o termo "etnomedicina" responde pelas crenças e práticas terapêuticas em contextos culturais marcados pela etnicidade. Envolve conhecimentos locais, incluindo a estrutura de parentesco, o pertencimento à terra e os sistemas linguísticos e mitológicos compartilhados (Greene, 1998; Langdon, 1996). Estes conhecimentos não são estáticos, mas estão em contínuas trocas com o mundo globalizado, por meio da urbanização, dos circuitos econômicos e dos sistemas públicos de saúde e educação.

Considerando estas práticas terapêuticas, a OMS lançou, em 2002, a Estratégia Medicina Tradicional, que busca desenvolver políticas nacionais para avaliação e regulação da medicina tradicional; criar forte evidência da segurança, eficácia e qualidade dos produtos e das práticas tradicionais; e documentar esta medicina e seus medicamentos. Entretanto, a orientação principal, com influência política sobre agências de saúde, requer que os saberes indígenas sejam enquadrados pela medicina ocidental, especialmente quando demanda "evidência, segurança e eficácia". Ao mesmo tempo, a OMS enfatiza a contribuição dos curadores tradicionais e suas práticas terapêuticas na atenção primária em saúde em países sul-americanos e orientais.

Em um levantamento realizado em 141 países, a OMS coletou dados sobre políticas nacionais, legislação e controle de plantas medicinais (WHO, 2005). Certas formas de medicina alternativa/complementar e tradicional ${ }^{5}$ desempenham um crescente e importante papel nos cuidados em saúde, afirma a OMS. $\mathrm{O}$ estudo destaca que as medicinas tradicionais sáo influenciadas por diferentes condiçôes históricas e culturais, mas insiste que "segurança, controle de qualidade e eficiência" são as maiores preocupaçóes das autoridades sanitárias (WHO, 2005: 5). Esses critérios constituem estágio compulsório ao reconhecimento destes saberes de modo a serem incorporados aos sistemas médicos convencionais, o que indica que as práticas indígenas de cura estão sob pressão para alterar seus métodos terapêuticos e suas bases epistemológicas para o padrão científico.

Bodeker e colegas $(2002,2007)$ confirmam o estabelecimento de diretrizes pelas instituiçóes sanitárias para a integração dos serviços de saúde alternativos, complementares e tradicionais, tais como pesquisa clínica, viabilidade econômica e fatores sociais e culturais. As plantas medicinais, por exemplo, constituem importante área em que o saber indígena tem atuado, mas que interessa também a corporaçóes farmacêuticas. Com relação a isto, os saberes tradicionais, tais como o xamanismo e a medicina das plantas, poderiam - contraditoriamente - contribuir para os empreendimentos médicos e biotecnológicos dominantes. 
Este fato indica que a indústria farmacêutica vive às expensas da herança natural indígena, como ocorre, por exemplo, com o grande interesse pela biodiversidade na floresta amazônica.

Krippner (Papas, Baydala \& Smythe, 2007) também destaca um modelo de compatibilidade entre etnomedicina e medicina alopática, tomando por exemplos o sistema de cura dos Navaho, nos Estados Unidos, e o xamanismo Paqokuna, no Peru. Mas chama a atenção para o forte poder da biomedicina diante dos sistemas tradicionais de cura. Faith Hill (2003), por sua vez, reconhece a importância da medicina complementar/alternativa (incluídos os saberes indígenas) para a promoção da saúde. Entretanto, assume que um desafio a ser superado é a inclusão dos aspectos espirituais da saúde. Bodeker e Gemma (2007) advertem que certos elementos dos cuidados tradicionais são removidos de seus contextos originais e incorporados ao sistema formal de saúde, o que traz problemas sobre como garantir a continuidade dos saberes indígenas. Por sua vez, Greene (1998) realça que, após o reconhecimento do pluralismo médico pela OMS, a integração da biomedicina com a etnomedicina foi encorajada, mas preservando a ideologia do progresso e o poder biomédico dominante, que depreciam as culturas tradicionais.

Todos estes estudos desenham um complexo cenário sobre as práticas de cura indígenas no mundo contemporâneo. Aspecto inevitável neste debateéa perspectiva da pluralidade terapêutica e da interculturalidade. Assim, concordamos com Leslie (1980), Helman (2007) e Kleinman (1978) que os sistemas médicos devem ser entendidos como estruturas pluralísticas, em que a medicina cosmopolita é um componente, entre outras opçóes terapêuticas, e a atenção em saúde assume distintos modos culturais de diagnóstico e tratamento de enfermidades. Assim, os elementos socioculturais são incontornáveis, revelando que diferentes formas de medicina ocorrem em contextos sociais vivos, com diversidade étnica, constrangimentos políticos, conflitos econômicos, prejuízos ao corpo e à saúde, e crenças mítico-religiosas. Estes aspectos são relevantes porque os esforços pela integração dos sistemas terapêuticos se fundamentam no reconhecimento das culturas indígenas e em seus métodos de cura (Brasil, 2002; Martin-Hill, 2009; Stephens et al., 2006). Tal fato repercute nas políticas públicas voltadas para a saúde indígena.

\section{Políticas públicas e saúde indígena no Brasil}

$\mathrm{O}$ reconhecimento das práticas indígenas de cura por governos e agências sanitárias é resultado dos movimentos indígenas em diferentes países, que reclamam por direitos indígenas e respeito a suas culturas. Esses esforços têm pressionado os governos a desenvolver políticas públicas, às vezes com poucos 
resultados, objetivando suplantar as difíceis condiçôes em que vivem esses povos (Bodeker \& Gemma, 2007; Montenegro \& Stephens, 2006; WHO, 2005). As populaçóes indígenas no Brasil têm sido longamente afetadas por doenças infecciosas, o que gerou grandes impactos demográficos e culturais. Ao longo dos séculos, a ordem colonial foi responsável pela opressão e marginalização dos povos indígenas enquanto construiu conceitos eurocêntricos sobre vida, morte, adoecimento e saúde.

O quadro da saúde dos povos indígenas no país é alarmante, conforme dados oficiais (Brasil, 2002) e estudos independentes (Garnelo \& Pontes, 2012; Ricardo \& Ricardo, 2011). Entre infecçóes e doenças parasitárias, a tuberculose tem sido responsável por um significativo número de mortes. A incidência de HIV/aids constitui outro sério problema no contexto de frágil cobertura em saúde, além de problemas de acessibilidade devido a obstáculos geográficos, econômicos e linguísticos. Langdon (2004) chama atenção para os altos índices de desnutrição, problemas de saúde bucal e mortalidade infantil nestas populaçóes. Organizaçóes indígenas confirmam altas taxas de alcoolismo, diabetes, hipertensão arterial, doenças sexuais, falta de condiçóes sanitárias e de suprimentos médicos, além das dificuldades para acesso aos serviços de saúde (Brasil, 2001, 2007a). Nos últimos 12 anos, diversas conferências indígenas em saúde reivindicaram a melhora das condiçóes de saúde indígena. Algumas demandaram programas para tuberculose e controle de HIV, serviços para a saúde da mulher e orientaçóes para a saúde de crianças e jovens (Brasil, 2001). Uma importante reivindicação é o apoio à saúde indígena mediante o respeito a seus sistemas de cura e a suas concepções culturais sobre corpo, saúde e enfermidades (Sesai, 2015).

$\mathrm{Na} 4^{\mathrm{a}}$ Conferência Nacional de Saúde Indígena (CNSI), uma forte preocupação foi direcionada aos curadores indígenas, às plantas medicinais e aos rituais indígenas (Brasil, 2007a). A conferência propôs ações (reunióes, workshops, legislação, proteção à biodiversidade) visando garantir uma parceria entre profissionais da saúde e curadores nativos. Já na 5a CNSI, realizada em 2013, uma das propostas aprovadas foi "valorizar as práticas da medicina tradicional indígena, reconhecendo e respeitando o conhecimento milenar, além de promover a interação entre a medicina indígena e a ocidental" (Sesai, 2015: 31).

De outro lado, por ocasião da Constituição de 1988, o Brasil foi considerado um Estado multiétnico no qual as populaçóes indígenas alcançaram maiores direitos de cidadania. O governo brasileiro reconhece o passado colonial destes povos, fortemente marcado por fragmentação social, discriminação cultural e violência. A inclusão dos direitos dos povos indígenas na Constituição preparou o caminho para o estabelecimento de programas para a saúde indígena. Isto se 
deu levando-se em conta o pluralismo médico e as particularidades étnicas dos saberes tradicionais. Nesse processo, em 1999 a saúde indígena tornou-se um setor da saúde pública nacional. Por decorrência, as políticas públicas pretendem reverter a situação das minorias excluídas mediante várias açôes. Contudo, para as organizaçóes indígenas, as políticas públicas resultam de conquistas sociais pelas comunidades indígenas para proteger seus direitos (Brasil, 2007a). Neste sentido, a política pública pode ser instrumento para estimular as práticas indígenas de cura, em uma necessária articulação com a biomedicina. A Política Nacional para os Povos Indígenas (Brasil, 2002) constitui um instrumento central desta estratégia, pois representa a proposição de um "modelo diferente" para a saúde indígena no SUS, visando

[...] garantir, aos povos indígenas, o acesso a um completo cuidado em saúde, conforme os princípios e diretrizes do Sistema Único de Saúde, cobrindo a diversidade social, cultural, geográfica, histórica e política no sentido de auxiliar a superar os fatores que tornam estas populaçôes vulneráveis aos problemas de saúde [...], reconhecendo a efetividade de sua medicina e o direito destas populaçôes a suas culturas (Brasil, 2002: 13).

$\mathrm{Na}$ diretriz sobre os sistemas tradicionais indígenas de saúde, o documento destaca que estes sistemas continuam sendo o recurso principal de atenção à saúde destes povos, mesmo convivendo com estruturas de saúde ocidentais (Brasil, 2002). Esta garantia legal é importante para os direitos indígenas, pois se reconhece a diversidade étnica, o respeito às culturas indígenas e a efetividade de sua medicina. Porém, a garantia formal contrasta com as lutas indígenas atuais. No Brasil, os grupos indígenas clamam pela redução da mortalidade e da desnutriçáo, e denunciam a falta de unidades de saúde e o baixo número de profissionais de saúde (Folha de S. Paulo, 2012). Em negociaçôes com autoridades brasileiras, os povos indígenas têm reivindicado suprimentos médicos, transporte, alimentos saudáveis e fortalecimento de sua medicina tradicional (Funai, 2012). Ao longo dos últimos dez anos, verifica-se uma incongruência da política de saúde indígena. Em vez de aprofundar a atençáo diferenciada, predomina o enfoque na doença, a medicalização e a desarticulaçáo dos cuidados tradicionais dos povos indígenas (Ricardo \& Ricardo, 2011).

Mesmo assim, o reconhecimento da medicina indígena pela política pública é aspecto central do pluralismo terapêutico, o que pode conduzir à cooperação entre os sistemas médicos. Por quê? Primeiramente, porque a efetividade das práticas indígenas de cura é oficialmente aceita; segundo, porque a "articulação da saúde indígena” constitui diretriz da política nacional (Brasil, 2002: 17). Ademais, 
o Ministério da Saúde indica que o incremento do status sanitário dos povos indígenas pode não ocorrer simplesmente pela transferência de conhecimento e tecnologia médica para as comunidades, uma vez que os povos indígenas não seriam "receptores passivos" das políticas públicas (Brasil, 2001: 17). Esta posição favorece a prática da medicina indígena, mas de outro lado indica que o poder biomédico pode comandar os esforços pela integração em seus próprios termos.

Outro aspecto de discussão é a política nacional que propóe o uso das práticas integrativas e complementares no SUS (Brazil, 2008). Esta ação é estratégica porque abre os serviços públicos para as terapias alternativas (acupuntura, homeopatia, fitoterapia, medicina antroposófica e hidroterapia). Este encaminhamento está alinhado às orientaçóes da OMS, que, com a medicina tradicional, favorecem os métodos complementares em saúde (WHO, 2002). No entanto, é relevante notar que apenas estes métodos terapêuticos foram aceitos no SUS até o momento, sendo "reconhecidos" pelo sistema biomédico dominante. As práticas de cura indígena não foram incorporadas ao SUS porque métodos nativos não são ainda cientificamente aprovados pelas autoridades sanitárias. Isto tem a ver com o fato de que, na medicina indígena, a eficácia terapêutica inclui elementos étnicos (língua, crenças religiosas, rituais mágicos) frequentemente não aceitos pela biomedicina.

Em acréscimo, experimentos e projetos em saúde indígena têm sido desenvolvidos, dentro da atenção primária em saúde, com parteiras tradicionais (Brasil, 2007b), plantas medicinais (Brazil, 2008) e rezadores (Andrade, 2010; Galindo, 2005) em diversas regiôes do Brasil. Mas alguns aspectos desta integração sociomédica permanecem controversos. Langdon (2007) expressa preocupação quanto à centralização das autoridades sanitárias, à hipermedicalização das comunidades nativas com medicamentos industrializados e ao desrespeito às particularidades étnicas dos povos indígenas. De modo semelhante, Ferreira (2007) critica as diretrizes da OMS porque elas requerem validação "científica" para as práticas indígenas de cura, observando que a integração constitui discurso normativo que se propóe, por meio da racionalidade biomédica, a controlar os saberes terapêuticos tradicionais. Ela enfatiza que os povos indígenas deveriam ter a liberdade de escolher e exercer sua lógica sociocultural nos espaços intermédicos.

Do ponto de vista do pluralismo médico, a inclusão dos métodos complementares nos serviços públicos, como mencionado antes, é importante marco para expandir as opçôes terapêuticas do povo brasileiro (Andrade \& Farias, 2010; Tesser \& Barros, 2008). Considerando estas mudanças institucionais, uma estratégia em interseção ganha crescente importância. É estimulada a cooperação entre conhecimentos não biomédicos e a medicina ocidental convencional, através dos serviços do SUS e do Disei; outra orientação visa estimular articulaçôes em 
múltiplos níveis da atenção em saúde, buscando uma abordagem holística do processo terapêutico. Neste esforço, a Secretaria especial da Saúde Indígena promoveu, em 2011, o workshop nacional Construindo as Linhas do Cuidado Completo na Rede de Saúde Indígena, objetivando articular práticas indígenas tradicionais com os serviços convencionais de saúde, o que é também uma reivindicação indígena (Brasil, 2007a). Este tipo de ação se propóe a garantir mais espaço para a medicina indígena como um instrumento para as políticas públicas no SUS, seguindo os exemplos da acupuntura e da homeopatia.

Conforme estabelecido pelas autoridades de saúde, as práticas indígenas de cura respondem "a uma lógica interna de cada comunidade", caracterizada pelo relacionamento com o meio ambiente e com o mundo espiritual. Este entendimento considera a diversidade de "visóes e valores relativos ao processo saúde/doença específicos de cada sociedade indígena” (Brasil, 2001: 18), isto é, a particularidade étnica e a intermedicalidade. De acordo com Greene, a intermedicalidade cobre "um espaço contextualizado de medicinas híbridas" (1988: 641). Este espaço configura o contexto comunitário em que enfermidades e seus processos de cura têm lugar (Ferreira, 2007). Ele emerge de um ethos local através de opçóes terapêuticas protagonizadas pela comunidade. No Brasil, este espaço dos sistemas híbridos de saúde é reconhecido como relevante para entender as práticas indígenas de cura e seu relacionamento com as políticas públicas (Follér, 2001, 2004; Novo, 2011; Rose, 2006). Um olhar endereçado às comunidades indígenas, onde as políticas de saúde atuam, pode esclarecer esta discussão.

\section{Povo Pitaguary: práticas de saúde e intermedicalidade}

Muitos povos indígenas no Nordeste brasileiro têm recebido apoio das redes Esf e Disei. No Ceará, o modo como os Pitaguary lidam com problemas de saúde, o relacionamento com serviços biomédicos e a presença de seus curadores tradicionais trazem luz para a presente reflexão.

Os Pitaguary da Monguba assumem distintos percursos terapêuticos no dia a dia. Estas práticas não se encontram desvinculadas, mas frequentemente estão em interface, dependendo dos problemas de saúde e das decisôes para enfrentá-los. "Medicina do homem branco" é a expressão utilizada por curadores e lideranças Pitaguary para se referirem aos serviços públicos de saúde. O termo apresenta uma dimensão étnica e política dentro da luta indígena. Os Pitaguary têm uma unidade de saúde da família, a Esf (para a população de não índios), e uma unidade de saúde indígena, o Disei. Essas agências incluem equipes multidisciplinares médico, dentista, enfermeira, assistente de enfermagem, agentes de saúde e de fiscalização sanitária —, mas frequentemente essas equipes não estão completas. 
Os serviços disponíveis incluem consultas, campanhas educacionais, visitas domiciliares e vacinaçôes, cobrindo uma variedade de enfermidades (hipertensão, diabetes, gripe, alcoolismo, diarreia, febre amarela, pneumonia, hepatite e câncer). Problemas de maior complexidade médica são encaminhados para hospitais fora da comunidade.

Através do Disei, os índios conseguem "atenção especial”, o que pressupóe que obtêm transporte, medicamentos e tratamentos para toda a comunidade, conforme estabelece a política nacional. Entretanto, estes serviços apresentam problemas de gestáo, de financiamento e de falta de profissionais, do mesmo modo como ocorre na rede SUS. A unidade do Disei na Monguba está aberta de segunda a sexta, combinando atendimentos no local e visitas domiciliares da equipe aos casos mais delicados, como idosos, crianças e hipertensos. Os Pitaguary buscam estes serviços, mas no cotidiano persistem no uso terapêutico das plantas, na consulta a rezadores e na participação de rituais. Em torno destes cuidados, o Pajé tem presença marcante, seja para providenciar curas e rezas, seja para oferecer aconselhamento espiritual.

Alguns curadores afirmam que, após a chegada da rede pública de saúde, muitas pessoas pararam de procurá-los, preferindo os serviços biomédicos. Eles também relatam que o consumo de medicamentos industrializados tem crescido, substituindo os medicamentos caseiros à base de plantas medicinais, especialmente entre os jovens.

Atualmente, as pessoas estão usando mais remédios artificiais. Eles esquecem a medicina da natureza, que é sagrada para nós. Eles não preparam sequer um chá. Somente no caso de uma leve dor de cabeça ou de dente é que eles preparam um chá. Mas no dia seguinte eles vão ao doutor, buscando uma consulta ou conseguindo um remédio artificial (curador 6).

Isto acontece porque a medicina indígena soluciona certas enfermidades de modo diferente da medicina convencional. $\mathrm{O}$ uso de ambas as medicinas é combinado:

é necessário utilizar a medicina do homem branco. Existem muitas plantas e chás que não podem curar certas doenças. Existem muitas doenças, e a cada dia outras novas aparecem. Nestes casos, se consegue um efetivo apoio da medicina do homem branco, como no caso da hepatite e da tuberculose. Nossa medicina pode ajudar alguns problemas, mas não todos (agente indígena de saúde).

Hoje a farmácia aconselha que nós combinemos nossa medicina com a deles. Semana passada eu curei meu filho, meu neto e eu mesmo. Eu usei remédio de farmácia e o doutor disse: faça seu lambedor e misture. Tudo deu certo (curador 3). 
De outro lado, tendo em conta as práticas indígenas de cura, uma universidade local desenvolveu, anos atrás, um treinamento sobre ervas medicinais. Os curadores participaram do curso e relataram que o acharam de algum modo útil, mas outros náo o consideraram proveitoso. $\mathrm{O}$ projeto pretendia inaugurar um horto de plantas medicinais, mas isto ainda não havia acontecido em 2011. Esta foi uma das poucas iniciativas institucionais tomadas para reunir os curadores. Outro dado importante, relativo à criação da Sesai, é revelado por uma agente indígena de saúde: "a saúde indígena da Sesai não anda paralelo com a saúde tradicional do povo pitaguary. Ela nem conhece”. A isto se soma a falta de treinamento para os agentes de saúde atuarem em território indígena e a ausência de valorização da medicina indígena por parte do Disei local.

\section{Plantas medicinais}

As práticas de cura entre os Pitaguary consideram que as açóes e os instrumentos biomédicos constituem o que eles nomeiam "medicina do homem branco". Esses índios dedicam atenção substantiva às atividades e aos instrumentos tradicionais que os ajudam a retirar da flora nativa raízes, cascas de plantas e folhas que constituem a matéria-prima para a solução de determinadas enfermidades, como envenenamento, anemia, dor de cabeça, constipaçáo, inflamaçóes, cansaço, caxumba e úlcera. Sobre o assunto nos relata um curador:

eu tomo as pílulas que eles me dão, mas eu confio mais nas plantas medicinais do que em remédio de farmácia. Eu confio na mãe natureza... quando a gente fica doente, nós usamos nossas plantas medicinais. Eu tenho uma grande fé em nossas plantas (curador 5).

Essa demasiada confiança na "mãe natureza" não evidencia uma valorização unilateral das curas tradicionais entre os Pitaguary, em detrimento das açóes ordinárias da biomedicina que ocorrem em suas aldeias. Para eles, a associação de soluçóes distintas para enfermidades semelhantes não diminui nem faz sobressair uma ou outra ação de cura. A associação de saberes nativos de sua flora com os conhecimentos da medicina convencional incrementa suas possibilidades de sanar certas dores físicas.

A medicina indígena é diferenciada. Você pode ver diversos tipos de medicina. Nós podemos usar nossos chás contra vírus, e podemos misturar com um analgésico. Isto dá uma boa infusão. Chá verde, como também erva-doce e erva-cidreira, podem ser tomados com qualquer remédio da medicina branca e não vai causar nenhum problema (curador 1). 
Das plantas locais que crescem nos quintais das casas e nas redondezas (malvarisco, hortelã, alecrim, jenipapo, babosa, mulungu, carrapateira, juá), os índios da Monguba preparam chás, lambedores, banhos e infusóes, seguindo a orientação de parentes, vizinhos, antigas parteiras e ancestrais. Mães, tias e avós são as primeiras guardiâs deste conhecimento, ao lado dos curadores nativos. $\mathrm{O}$ uso das plantas medicinais é, neste caso, extensivo à manipulação de animais (banha, pele, penas, vísceras etc.), tais como sapo, urubu, cobra, cágado e tijuaçu, naturais do território pitaguary, com os quais os índios têm familiaridade, servindo de ingredientes para seus cuidados de saúde. Tudo isso sem negar os caminhos que a biomedicina indica.

\section{Toré: instrumento de cura espiritual}

O ritual do Toré constitui cerimônia central dos Pitaguary e de outros povos do Nordeste. É uma dança organizada com índios de pé no chão a formar um grande círculo dentro do qual é disposta uma roda menor, onde certas lideranças vultosas, como o Pajé, um professor indígena destacado, uma reconhecida curadora e o Cacique, por exemplo, entoam cânticos e apelos. Esses líderes têm o papel principal de orientar os tons e as espiritualidades da performance ritual (Turner, 1974) por meio do anúncio de letras em sons graves, agudos e altos a fim de que todos na grande roda possam escutar as cançôes, avolumar o coro em uníssono e assemelhar os estados de espírito para propósitos determinados.

Passados alguns instantes da entonação solitária de uma das lideranças que compóe o círculo menor, esse arredondado inicia um movimento encíclico imediatamente acompanhado por todos que participam da cerimônia. Os corpos movimentam-se com os arrastados dos pés descalços, os balanços das mãos, as inclinaçóes da cabeça para os lados e o abrir e fechar dos olhos. Toda essa animação é, habitualmente, realizada em sentido anti-horário e ritmada ao som de tambor, maracás e vozes de crianças, jovens e adultos. Seus corpos são ornados com desenhos de cores e formas representativas de paisagens naturais, pelejas políticas, elementos espiritualistas, sentimentos de pertença etc., acompanhados de adornos tradicionais, como cocares de penas de aves locais, pulseiras, brincos e colares confeccionados com sementes da flora nativa. As sessóes que envolvem o Toré possuem intervalos de tempo distintos, podendo incidir em alguns minutos ou se alongar por fraçóes de horas.

A cerimônia do Toré entre os Pitaguary pode segmentar uma tríade ordenação com base na participação indígena e de não índios nesse ritual. $\mathrm{O}$ primeiro segmento, que classificamos de étnico, permite apenas que índios da referida 
etnia participem da cerimônia; o segundo, que ordenamos interétnico, contempla duas ou mais etnias em suas rodas de celebração; por terceiro, identificamos o Toré público, isto é, aquela modalidade organizacional aberta à participação de qualquer pessoa, seja ela índia ou náo. Mesmo apresentando esses limites de participação, há um propósito que perpassa por todas as manifestaçóes e que pode ser observado com maior ou menor intensidade a depender da situação e da qualidade da participação nas rodas: a dimensão sagrada do Toré, que proporciona aos indígenas o abrandamento ou a solução definitiva de certos males (encosto, possessão, perturbação mental) que acometem o seu bem-estar espiritual.

Este aspecto do ritual encontra abrigo reflexivo nas ponderaçóes de Greene (1998) sobre intermedicalidade. As curas tradicionais que têm lugar na cerimônia do Toré constituem parte de um "espaço contextualizado" em que diversas respostas ao enfrentamento das enfermidades são postas em uso, incluindo os aconselhamentos e tratamentos médicos do Disei. Modo semelhante de pensar é apresentado por Follér (2004) quando identifica uma "zona de contato" onde são estabelecidas relações legítimas entre as práticas de curas indígenas e aquelas realizadas pela medicina convencional.

Nestes termos, a dimensão sagrada do Toré proporciona a elaboração de demandas indígenas por serenamento ou mesmo a colocação de termo final em debilidades de várias ordens. As solicitaçóes dos índios aos parentes desencarnados, denominados de encantados, são realizadas em voz alta ou em recluso pensar ao longo dessa manifestação cerimonial e podem ser ordenadas em dois grupos: as requisiçôes individuais e coletivas. No caso das primeiras, as rogas intentam alcançar decisôes espirituais que solucionem demandas por saúde espiritual ou orgânica daqueles que propagam as requisiçôes na roda do Toré ou para indivíduos que não se encontram presentes no ritual, mas que carecem de ajuda incorpórea de determinada qualidade. No tocante às solicitaçóes coletivas, os direcionamentos dos apelos recaem sobre a totalidade da etnia local ou são conduzidos para índios pertencentes a outros grupos étnicos que necessitam de amparo, habitualmente de ordem social. Do modo individual ou da maneira coletiva, é recorrente entre os curadores indígenas a afirmação da presença de uma energia dos encantados, imersa no ritual do Toré, manifestando-se frequentemente em corpos que tremem e entram em transe.

Nós cantamos o Toré, nós dançamos o Toré e damos oportunidade para que as entidades venham para a roda, para transmitir energia e força. Às vezes as pessoas tremem e às vezes podem entrar em transe quando dançam o Toré (curador 1). 
Nestas situações cerimoniais, os caminhos para as curas são percorridos deliberadamente por índios que objetivam construir um elo e uma legitimidade com os encantados. Isso porque, para a solicitação ser alcançada, é necessário que a súplica seja voluntária e precisa para o espírito ou o corpo que requer a abreviação ou o término de dores. Outro curador nos narra:

as pessoas se curam porque o Toré é uma coisa que nós fazemos como ritual particular [...]. Nós fazemos para fortalecer a espiritualidade de cada um. Sobre a cura do corpo, depende de cada pessoa [...]. Eu quero ser curado, eu sei que aquelas rezas são fortes e podem me aliviar [...]. A cura não é apenas física, mas também espiritual (curador 2).

Com o encerramento da cerimônia, os indígenas que apelaram com mais intensidade aos encantados presentes na roda do Toré sentem-se acalmados e percebem uma melhora na sua condição espiritual. Por outro lado, os índios que não alcançaram seus propósitos de cura se sentem enfastiados e com sinais de tremor, frio e medo, conforme nos relata um curador:

o Toré significa purificação e ritual sagrado. Se alguém não consegue uma melhora, sente arrepios e fica mole, o vento limpa ele. Quando o Toré acaba, todos voltam calmos para casa, com sono e acordam bem no dia seguinte (curador 7).

Importa sublinhar que, ao longo do Toré, alguns Pitaguary ingerem uma bebida produzida com base em raízes e/ou cascas da planta nominada jurema, que possui qualidades sagradas e pode acarretar efeitos alucinógenos. Segundo os curadores, a ingestáo desse composto aperfeiçoa o encontro espiritual com os encantados e esmera as possibilidades de encontrar as curas requeridas.

\section{Tratamentos espirituais}

Em alguns casos, os curadores diferenciam doenças físicas e espirituais. $\mathrm{Na}$ comunidade pitaguary, problemas espirituais (como feitiçaria) são tratados com certas práticas de cura: rezas, rituais de umbanda e cerimônias em igrejas cristâs. A reza consiste em rito com influência do catolicismo popular, da umbanda e de igrejas evangélicas. Trata-se de um procedimento no qual o rezador calcula as medidas corporais e reza com imposição de mãos e ramos de plantas sobre o corpo do paciente, fazendo uso de rezas específicas para cada tipo de enfermidade (mau-olhado, susto, inveja, dores de coluna, cobreiro). Em certas ocasiôes, incluem-se rezas para tratar de animais (gatos, cães, vacas). De maneira especial, as curas por meio de rezas fazem com que a doença que impregna a pessoa seja extraída das camadas que compóem o corpo até que o curador possa enviá-la ao oceano sagrado. 
Às vezes, é alguma coisa nos ossos. Ele reza, é uma bonita reza. Ele faz a dor ir embora, nós sentimos isto. Ele tira a dor do tutano para os ossos, dos ossos para a carne, da carne para a pele, e entáo manda para as sete ondas do mar sagrado (curador 9).

Em outras situaçóes, a relação entre a biomedicina e as curas tradicionais torna-se convergente quando ambas intentam sanar mazelas que acometem as crianças. Nesses casos, os índios procuram médicos considerando que os remédios industrializados receitados por esses especialistas possam findar os males que abatem certas crianças. Todavia, quando essas prescrições médicas não funcionam, os indígenas procuram imediatamente um curador da aldeia:

quando uma criança para de comer e não quer o leite da mãe, os pais levam para o médico. Então ele recomenda um remédio para abrir o apetite. Quando isto não funciona, eles procuram um rezador. Nosso povo diz que a vida de uma criança está nas mãos de um curador (curador 10).

As curas indígenas são cerimoniadas, de quando em vez, por elementos da espiritualidade que remetem com clareza à prática da umbanda. Trata-se de um complexo ritual baseado no sincretismo religioso envolvendo o candomblé africano, o catolicismo popular e os rituais indígenas. $\mathrm{Na}$ comunidade pitaguary, existem três terreiros de umbanda. Um dos grupos, liderado pelo Pajé da comunidade, está localizado na Monguba. Índios evangélicos, católicos e não índios buscam o Pajé para rezas, sessóes de umbanda e cerimônias de cura. Entre os instrumentos de que esse curador lança mão para transmitir ensinamentos e findar males espirituais em índios demandados estão as incorporaçôes de encantados. O Pajé cerimonializa a vinda de espíritos desencarnados que têm a missão de fazer uso de seu corpo a fim de produzir o bem-estar espiritual ou físico daquelas pessoas que se encontram presentes na sessão e que solicitam o término de suas dores. Sobre o tema nos fala um curador:

o céu dos índios é o mundo encantado. Nosso céu é a mata. Os encantados são índios que permanecem na floresta, em muitas tribos. Então, o presente do Pajé é exatamente doar seu corpo para aquelas entidades para trazer ensinamentos e experiências... assim, nossa igreja é a serra e a mata (curador 1).

A participaçáo recorrente desses índios em cerimônias tradicionais de cura não implica que eles não praticam outras formas de espiritualidade. As igrejas evangélicas, como Comunidade Bíblica da Graça, Assembleia de Deus, Igreja Universal e Deus é Amor, além da Católica Apostólica Romana, têm número considerável de seguidores entre os Pitaguary. Esse hibridismo de espiritualidades e religiôes, contudo, não recai em preconceito. Essa diversidade de ritos e sentidos espirituais é respeitada. 
Hoje nós temos uma quantidade de seitas em nossa aldeia e nós respeitamos cada uma delas. Qualquer índio pode seguir sua seita e a gente náo interfere. Eu prefiro uma diversidade de seitas, que é bem melhor do que uma diversidade de forró (curador 1).

De modo particular, os rituais organizados pelas igrejas evangélicas são apreendidos por esses índios como cerimônias que se aproximam, em termos dos seus propósitos, daqueles tradicionalmente praticados pelos Pitaguary. Entre as diferenças indicadas por eles está o fato de os rituais evangélicos não lançarem mão de plantas medicinais. Todavia, o problema espiritual estando presente, as igrejas evangélicas procuram afastar as doenças espirituais, assim como as cerimônias indígenas de cura o fazem: "as igrejas evangélicas vieram para nossa aldeia. Entre eles, ficar curado não é muito usando plantas medicinais, mas é uma questão espiritual. Qualquer um que enfrente problemas espirituais vai para uma igreja evangélica" (curador 8). Algumas pessoas afirmam existir uma pressão da parte dos evangélicos para que os índios deixem suas práticas tradicionais e espiritualidade em favor dos ritos cristáos, o que traz desconforto entre eles.

De outro lado, conforme as lideranças Pitaguary, desordens físicas e espirituais estão, em muitos casos, misturadas. Mas há ocasiôes em que o curador diagnostica que a enfermidade tem origem espiritual. Quando não é o caso, o paciente é encaminhado para o posto de saúde. O contrário igualmente acontece. Integrantes da equipe de saúde (médicos e assistentes) por vezes aconselham que os pacientes façam uso de chás e rezas em associação com os tratamentos convencionais. Finalmente os curadores, como também os pacientes, partilham crenças populares sobre as plantas, os animais, a floresta e as entidades espirituais, o que é relativamente comum entre comunidades nativas em áreas rurais do Ceará.

Para lidar com a saúde, as estratégias utilizadas pelos Pitaguary confirmam o pluralismo terapêutico, incluindo a biomedicina, representada pela Esf e Disei. Isto ocorre no interior da comunidade, na vida diária das pessoas. Curas de doenças físicas e espirituais são obtidas na roda de Toré, nas rezas, em rituais evangélicos, em sessões de umbanda. Por sua vez, os serviços biomédicos são bem-vindos, porque fortalecem a saúde dos Pitaguary, mas estão combinados a crenças indígenas e práticas nativas assumidas por livre iniciativa das pessoas. A maneira como os índios manejam sua saúde, embora náo constitua um recurso terapêutico em sentido restrito, é característica da identidade étnica. Os Pitaguary se reconhecem como índios por causa de seus ancestrais, da relaçáo com a terra, de suas festas e cerimônias, mas também por conta de seus tratamentos de cura e rituais, em uma variedade de crenças, como ocorre com outros povos (MartinHill, 2009; Obomsawin, 2007). 
No contexto comunitário, a diversidade de opções de saúde entre os Pitaguary persiste e se manifesta nas trocas locais de conhecimentos e cuidados terapêuticos, em formas criativas, atendendo dimensóes plurais da condição humana. A intermedicalidade náo apenas ilumina as transaçóes entre biomedicina e etnomedicina, protagonizadas pelos índios; ela também revela que o espaço das "medicinas híbridas" é assumido pela comunidade, conforme costumes familiares, crenças religiosas e tradiçóes indígenas, com acordos e disputas.

Neste "espaço contextualizado" (Greene, 1998) habitam os Pitaguary. Tratase de uma zona de contato (Follér, 2004) entre saberes e práticas heterogêneos, um espaço múltiplo, rico e contraditório, cujos sujeitos não são "receptores passivos" das políticas públicas, mas agentes criativos de sua saúde, mesmo que enfrentando a pobreza e escassez de recursos. A comunidade constrói itinerários terapêuticos e se apropria de opções médicas em um cenário intercultural onde atuam profissionais e unidades de saúde, igrejas e curadores.

\section{Conclusáo}

Neste artigo, abordamos as práticas indígenas de cura em uma perspectiva antropológica como recurso terapêutico aos serviços de saúde. Pelo exame de agências sanitárias e do discurso oficial dos órgãos de saúde, analisamos a integração, assunto incluído em políticas públicas e relatórios técnicos. No Brasil, a criação do setor de saúde indígena configura importante passo para o reconhecimento das práticas nativas de cura. Isto resulta da luta indígena ao longo de muitos anos buscando proteger sua cultura, com o apoio de movimentos sociais e instituiçóes. Neste contexto, as políticas públicas estão sob pressão de forças políticas, e a biomedicina opera como modelo sanitário colonizador dentro dos serviços de saúde.

As açóes públicas em saúde voltadas para as comunidades indígenas promovem um intercâmbio limitado, em vez de uma integração de sistemas médicos. A este respeito, um ponto central é que a diversidade terapêutica está fundamentada em forças sociais e culturais, o que acontece em distintas sociedades. O setor popular dos cuidados em saúde constitui exemplo significativo, com grande capilaridade na sociedade brasileira.

No caso dos Pitaguary, exploramos estes elementos étnicos em uma variedade de usos. A intermedicalidade, ao invés da integração, apresenta um quadro mais realista de como a comunidade local lida com seus recursos de saúde. Claro que, por muitas razóes (pobreza, exclusão social, qualidade de vida), os Pitaguary aceitam os serviços biomédicos como direito legítimo de cidadania. No entanto, 
por motivos políticos e étnicos, eles necessitam preservar as práticas nativas de cura. Adota-se então uma espécie de estratégia mista, em que as medicinas híbridas têm lugar e, certamente com disputas e diferenças, a diversidade terapêutica segue em frente. Assim, a intermedicalidade realça o contexto de culturas híbridas, que opera em diferentes níveis e modos, a partir de distintas epistemologias. Trata-se, portanto, não de integração, mas de convívio entre saberes de cura. Julgamos que esta reflexão pode lançar luzes contributivas para compreender com mais densidade a rica relaçáo entre as curas indígenas tradicionais e a medicina convencional.

Recebido em: 21/11/2014

Aprovado em: 30/11/2016

João T. Andrade é Doutor em Antropologia, com formação na Universidade Federal da Bahia, Case Western Reserve University (EUA) e Pós-doutoramento na University of Toronto (Canadá). É Pesquisador e docente do Programa de PósGraduaçáo em Sociologia da Universidade Estadual do Ceará (UECE). E-mail: joao.andrade@uece.br

Carlos Kleber Saraiva de Sousa é Mestre e Doutor em Sociologia pela Universidade Federal do Ceará (UFC). Professor e pesquisador em Antropologia do Departamento de Ciências Sociais da UFC. Coordenador da Licenciatura Intercultural Indígena PITAKAJA da UFC. E-mail: klebersaraivaufc@gmail.com 


\section{Notas}

1. No original em inglês: "a contextualized space of hybrid medicines and sociomedically conscious agents".

2. Dados oficiais da Sesai, mas estes números diferem. Há mais comunidades a considerar, segundo as organizaçóes indígenas do Ceará.

3. Projeto Saúde indígena no Ceará: especialistas e práticas tradicionais em culturas diferenciadas, financiado pelo CNPq, Edital MCT/CNPq/MEC/Capes n. 02/2010.

4. João T. Andrade agradece ao Centre for Critical Health Research at University of Toronto e ao Prof. Blake Poland por um período de 1 ano (2011/2012) de permanência como professor visitante, através de bolsa PDE do CNPq. Agradecimentos também para Liduina Farias, Sônia Lima e para as assistentes de pesquisa Rebeca Brito, Gabriela Colares, Jairla Pedroza e Sheylliane Lopes da UECE.

5. "Tradicional" refere-se a práticas e saberes médicos alicerçados longamente na cultura local; alternativo/complementar diz respeito a cuidados terapêuticos oriundos de outras sociedades.

\section{Referências}

ANDRADE, João T. 2010. "Ritos terapêuticos entre rezadores no Grande Bom Jardim, em Fortaleza: persistência dos saberes comunitários em saúde". Anais da 27a Reunião Brasileira de Antropologia. Brasília: Associação Brasileira de Antropologia.

ANDRADE, João T. \& FARIAS, Liduina. 2010. "Medicina Complementar no SUS: práticas integrativas sob a luz da Antropologia médica”. Saúde e Sociedade, 19(497-508).

BODEKER, Gerard \& GEMMA, Burford (eds). 2007. Traditional, complementary and alternative medicine: policy and public health perspective. London: Imperial College Press.

BODEKER, Gerard. \& KRONENBERG, Fredi. 2002. "A public health agenda for traditional, complementary, and alternative medicine". American Journal of Public Health, 92(10): 1582-1591.

BRASIL. Conselho Nacional de Saúde. 2001. $3^{a}$ Conferência Nacional de Saúde Indígena. Luziânia, GO. Disponível em: http://dab.saude.gov.br/docs/geral/3cnsi.pdf. Acesso em: $12 / \mathrm{mar} / 2013$.

Fundação Nacional de Saúde. 2002. Política nacional de atençâo à saúde dos povos indígenas. Brasília: Ministério da Saúde. Fundação Nacional de Saúde. 
. Fundação Nacional de Saúde. 2007a. $4^{o}$ Conferência Nacional de Saúde Indigena. Brasília, DF. Disponível em: conselho.saude.gov.br/biblioteca/Relatorios/ relat_final_4CNSI.pdf. Acesso em: 25/nov/2012.

. Ministério da Saúde. Fundação Nacional de Saúde. 2007b. "Medicina tradicional indígena em contextos". In: Luciane O. Ferreira \& Patrícia S. Osório (orgs.). Anais da I Reunião de Monitoramento. Brasília: Projeto Vigisus II/Funasa.

BRAZIL. Ministry of Health of Brazil. 2008. PNPIC: National Policy on Integrative and Complementary Practices of the SUS: access expansion initiative. Brasilia: Ministry of Health of Brazil, Secretary of Health Care, Department of Primary Care.

BROADHEAD, Lee-Anne, \& HOWARD, Sean. 2011. "Deepening the debate over 'sustainable science': indigenous perspectives as a guide on the journey". Sustainable Development, 19(5): 301-311.

FERREIRA, Luciane O. 2007. "Limites e possibilidades da articulação entre as medicinas tradicionais indígenas e o sistema oficial de saúde”. In: Luciane O. Ferreira \& Patrícia S. Osório (orgs.). Anais da I Reuniāo de Monitoramento. Brasília: Projeto Vigisus II/Funasa. 166-174.

FOLHA DE S. PAULO. 2012. Índios ocupam prédios e boqueiam rodovias para cobrar atenção à saúde. 29 de maio. Disponível em: http://memoria.ebc.com.br/agenciabrasil/ noticia/2012-05-29/indios-ocupam-predios-e-bloqueiam-rodovias-para-cobrar-atencaosaude. Acesso em: 23/set/2012.

FOLLÉR, Maj-Lis. 2001. "Interactions between global processes and local health problems. A human ecology approach to health among indigenous groups in the Amazon". Cadernos de Saúde Pública, 17(Suplemento): 115-126.

. 2004. "Intermedicalidade: a zona de contato criada por povos indígenas e profissionais de saúde”. In: LANGDON, Esther J. M. \& GARNELO, Luiza. (orgs.). Saúde dos povos indigenas: reflexóes sobre antropologia participativa. Rio de Janeiro: Contra Capa Livraria/Associação Brasileira de Antropologia. 129-147.

FUNDAÇÃO NACIONAL DO ÍNDIO (FUNAI). 2012. Saúde indígena foi tema predominante no encerramento da CNPI. 8 de junho. Disponível em: http://www.funai. gov.br/index.php/comunicacao/noticias/1721-saude-indigena-foi-tema-predominanteno-encerramento-da-cnpi. Acesso em: 15/nov/2012.

GALINDO, Daniel. 2005. "A inclusão das rezadoras de Maranguape na promoção da saúde pública”. Revista Acadêmica do Grupo Comunicacional de São Bernardo, 2(3): 1-16.

GARNELO, Luiza \& PONTES, Ana L. (orgs.). 2012. Saúde indigena: uma introdução ao tema. Brasília: Ministério da Educação; Unesco. 
GREENE, Shane. 1998. "The shaman's needle: development, shamanic agency, and intermedicality in Aguaruna lands, Peru”. American Ethnologist, 25(4): 634-658.

HELMAN, Cecil G. 2007. Culture, health and illness. London: Hodder Arnold.

HILL, Faith J. 2003. "Complementary and alternative medicine: the next generation of health promotion?” Health Promotion International. 18(3): 265-272.

KLEINMAN, Arthur. 1978. "Concepts and a model for the comparison of medical systems as cultural systems". Social Science and Medicine, 1(12): 85-93.

LANGDON, Esther J. M. (org.). 1996. Xamanismo no Brasil: novas perspectivas. Florianópolis-SC: UFSC.

. 2004. "Políticas públicas de saúde indígena: implicações para minorias e saúde reprodutiva”. In: S. Monteiro \& L. Sansone (orgs.). Etnicidade na América Latina: um debate sobre raça, saúde e direitos reprodutivos. Rio de Janeiro: Fiocruz. 211-226.

2007. "Problematizando os projetos de medicina tradicional indígena". In: Luciane O. Ferreira \& Patrícia S. Osório (orgs.). Anais da I Reunião de Monitoramento. Brasília: Projeto Vigisus II/Funasa.110-119.

LESLIE, Charles. 1980. "Medical pluralism in world perspective". Social Science \& Medicine, 14B: 191-195.

MARTIN-HILL, Dawn. 2003. Traditional medicine in contemporary contexts: protecting and respecting indigenous knowledge and medicine. Ottawa: National Aboriginal Health Organization.

2009. "Traditional medicine and restoration of wellness strategies". Journal of Aboriginal Health, 5(1): 26-42.

MONTENEGRO, Raul A. \& STEPHENS, Carolyn. 2006. "Indigenous health in Latin America and the Caribbean”. Lancet, 367: 1859-1869.

NOVO, Marina P. 2011. "Política e intermedicalidade no Alto Xingu: do modelo à prática de atenção à saúde indígena”. Cadernos de Saúde Pública, 27(7): 1362-1370.

OBOMSAWIN, Raymond. 2007. Traditional medicine for Canada's first peoples. Report.

PAPPAS, James D., BAYDALA, Angelina \& SMYTHE, Willian E. (eds). 2007. Cultural healing and belief systems. Galgary: Detselig.

ROSE, Isabel S. 2006. "Cura espiritual, biomedicina e intermedicalidade no Santo Daime”. In: 25a Reunião Brasileira de Antropologia. Goiânia: ABA. 
RICARDO, Beto \& RICARDO, Fany (eds). 2011. Povos indígenas no Brasil 2006/2010. São Paulo: Instituto Socioambiental.

SECRETARIA ESPECIAL DE SAÚDE INDÍGENA (SESAI). 2015. Relatório da $5^{a}$ Conferência Nacional de Saúde Indigena. Brasília: Ministério da Saúde.

STEPHENS, Carolyn, PORTER, John, NETTLETON, Clive \& WILLIS, Ruth. 2006. "Disappearing, displaced, and undervalued: a call to action for indigenous health worldwide". Lancet, 367:2019-2028.

TESSER, Charles D. \& BARROS, Nelson F. 2008. "Medicalização social e medicina alternativa e complementar: pluralização terapêutica do Sistema Único de Saúde". Revista Saúde Pública, 42(5): 914-920.

TURNER, Victor. 1974. O processo ritual. Petrópolis-RJ: Vozes.

WALDRAM, James B., HERRING, Ann H. \& YOUNG, T. Kue. 2006. Aboriginal health in Canada: historical, cultural, and epidemiological perspectives. Toronto, Buffalo, London: University of Toronto Press.

WORLD HEALTH ORGANIZATION (WHO). 2002. WHO traditional medicine strategy 2002-2005. Geneva.

_-____. 2005. National policy on traditional medicine and regulation of herbal medicines. Geneva. 


\section{Resumo}

Em muitos países, agências de saúde e governos têm proposto uma integração entre diferentes sistemas médicos dentro de serviços públicos nacionais. No Brasil, a inclusão das terapias complementares e tradicionais no Sistema Único de Saúde constitui importante marco para a expansão das opçóes terapêuticas da população. Quais são as implicaçóes deste empreendimento? Este artigo constitui uma reflexão sobre práticas indígenas de cura no Nordeste brasileiro como recurso terapêutico aos serviços convencionais de saúde e contribui para o debate sobre a diversidade dos sistemas médicos. Trata-se de exame das políticas públicas e diretrizes oficiais de saúde que propóem a integração da biomedicina com as práticas terapêuticas indígenas. $\mathrm{O}$ assunto é discutido considerando-se o pluralismo médico e a intermedicalidade, entendida como espaço contextualizado de medicinas híbridas. A discussão está baseada em revisão de literatura especializada, pesquisa documental e etnografia do povo Pitaguary no Nordeste do Brasil. A intermedicalidade ilustra uma forma particular de cuidados de saúde, tendo em conta crenças culturais e práticas terapêuticas articuladas a interesses e costumes das comunidades indígenas, pondo em contato vários elementos culturais.

Palavras-chave: Práticas indígenas de cura, medicina tradicional, políticas públicas, intermedicalidade, pluralismo médico.
In several countries, health agencies and governments are proposing an integration of different medical systems into national public services. In Brazil, the inclusion of complementary and traditional therapies into the Unified Health System is an important milestone to expand the therapeutic options of the population. What are the implications of such an endeavor? This article is a reflection on Indigenous Healing Practices in Northeast Brazil as a therapeutic resource for conventional health services; also, it contributes to the debate on the diversity of medical systems. It is an examination of public policies and official health guidelines that propose to integrate biomedicine and indigenous therapeutic practices. The subject is discussed considering medical pluralism and intermedicality, a contextualized space of hybrid medicines. The discussion is based on academic literature review, document review, and an ethnography of the Pitaguarypeoplein the Northeast Brazil. Intermedicality shows a particular form of health care, considering cultural beliefs and therapeutic practices from local community interests and customs within indigenous communities. Also, it puts together various cultural elements.

Keywords: Indigenous healing practices, traditional medicine, public policies, intermedicality, medical pluralism. 